\title{
Article \\ IGFBP7 Concentration May Reflect Subclinical Myocardial Damage and Kidney Function in Patients with Stable Ischemic Heart Disease
}

\author{
Anna Lisowska ${ }^{1, *}$, Anna Szyszkowska ${ }^{1}$, Małgorzata Knapp ${ }^{1}$, Magda Lapińska ${ }^{2}$, Marcin Kondraciuk ${ }^{2}$, \\ Inga Kamińska ${ }^{3}$, Tomasz Hryszko ${ }^{4}$ (D), Katarzyna Ptaszyńska-Kopczyńska ${ }^{1}$ and Karol Kamiński ${ }^{1,2} \mathbb{D}$ \\ 1 Department of Cardiology, Medical University of Bialystok, 15-276 Bialystok, Poland; \\ annaszyszkowska92@gmail.com (A.S.); malgo33@interia.pl (M.K.); \\ katarzyna.ptaszynskak@gmail.com (K.P.-K.); fizklin@wp.pl (K.K.) \\ 2 Department of Population Medicine and Lifestyle Diseases Prevention, Medical University of Bialystok, \\ 15-276 Bialystok, Poland; magda.lapinska@umb.edu.pl (M.Ł.); marcin.kondraciuk@umb.edu.pl (M.K.) \\ 3 Department of Integrated Dentistry, Medical University of Bialystok, 15-276 Bialystok, Poland; \\ inga.kaminska@umb.edu.pl \\ 4 2nd Department of Nephrology, Medical University of Bialystok, 15-276 Bialystok, Poland; \\ tomasz.hryszko@umb.edu.pl \\ * Correspondence: anlila@poczta.onet.pl; Tel.: +48-85-831-8656
}

Citation: Lisowska, A.; Szyszkowska,

A.; Knapp, M.; Łapińska, M.;

Kondraciuk, M.; Kamińska, I.;

Hryszko, T.; Ptaszyńska-Kopczyńska,

K.; Kamiński, K. IGFBP7

Concentration May Reflect

Subclinical Myocardial Damage and

Kidney Function in Patients with

Stable Ischemic Heart Disease.

Biomolecules 2022, 12, 274. https://

doi.org/10.3390/biom12020274

Academic Editor: Christian Schulz

Received: 12 January 2022

Accepted: 1 February 2022

Published: 8 February 2022

Publisher's Note: MDPI stays neutral with regard to jurisdictional claims in published maps and institutional affiliations.

Copyright: (C) 2022 by the authors. Licensee MDPI, Basel, Switzerland. This article is an open access article distributed under the terms and conditions of the Creative Commons Attribution (CC BY) license (https:// creativecommons.org/licenses/by/ $4.0 /)$.

\begin{abstract}
The objective of this study was to determine the associations between insulin-like growthfactor-binding protein 7(IGFBP7) concentrations and concentrations of troponin T(TnT), N-terminal pro-B-type natriuretic peptide(NT-proBNP) and the parameters of kidney function in patients with stable ischemic heart disease(IHD). The IHD group consisted of 88 patients, and the population group comprised 66 subjects without a history of IHD. IGFBP7, TnT and NTproBNP concentrations were measured. The IGFBP7 value was considerably higher in the IHD group $(1.76 \pm 1 \mathrm{ng} / \mathrm{mL}$ vs. $1.43 \pm 0.44 \mathrm{ng} / \mathrm{mL}$, respectively, $p=0.019)$. Additionally, IHD subjects had a significantly higher concentration of TnT and NTproBNP. In both groups there was a significant correlation between IGFBP7 and serum parameters of kidney function (creatinine concentration: population $\mathrm{gr} . \mathrm{r}=0.45$, $p<0.001$, IHD gr. $\mathrm{r}=0.86, p<0.0001$; urea concentration: population gr. $\mathrm{r}=0.51, p<0.0001$, IHD gr. $\mathrm{r}=0.71, p<0.00001$ ). No correlation between IGFBP7 and microalbuminuria or the albumin to creatinine ratio in urine was found. Moreover, there was a significant correlation between IGFBP7 concentration and markers of heart injury/overload-TnT and NT-BNP( $\mathrm{r}=0.76, p<0.001$ and $\mathrm{r}=0.72$, $p<0.001$, respectively). Multivariate regression analysis in joint both revealed that the IGFBP7 concentration is independently associated with urea, creatinine and TnT concentrations $\left(\mathrm{R}^{2}\right.$ for the model 0.76). IHD patients presented significantly higher IGFBP7 concentrations than the population group. Elevated IGFBP7 levels are associated predominantly with markers of kidney function and myocardial damage or overload.
\end{abstract}

Keywords: ischemic heart disease; heart failure; IGFBP-7; NTproBNP; troponin T

\section{Introduction}

Ischemic heart disease (IHD), due to the declining prevalence of hypertension and valvular heart disease, is the most common cause of heart failure (HF) in developed countries [1,2]. According to epidemiological data, IHD globally affects around 126 million individuals (1655 per 100,000), which is approximately $1.72 \%$ of the world's population, and its prevalence is rising [3]. IHD contributes to both HF with reduced ejection fraction (HFrEF) and HF with preserved ejection fraction (HFpEF) and it is related with a poor prognosis [1]. In order to diagnose, assess and monitor patients with HF and IHD, markers of heart injury are measured. The most common are troponin T (TnT) and NTproBNP. Their elevated levels are proven to be associated with worse clinical outcomes and further 
development of HF, even in patients with a preserved ejection fraction [4-6]. However, their evaluation in daily medical practice is sometimes not sufficient to make an accurate diagnosis, and there is need to find new markers that help resolve this issue. Recently, more attention has been drawn to the effects of insulin-like growth-factor-binding protein 7 (IGFBP7) as a marker of cellular senescence, insulin resistance and atherosclerosis. IGFBP7 is a $30-\mathrm{kDa}$ modular secreted protein, which is also called mac25, tumor adhesion factor (TAF), the prostacyclin-stimulating factor (PSF) or angiomodulin. IGFBP7 is a part of the insulin-like growth factor system, which is involved in the growth, proliferation and differentiation of human cells $[7,8]$. According to an increasing body of evidence, the insulin-like growth factor system could play an important role in the highly complex pathogenesis of atherosclerosis. IGF-1 (insulin-like growth factor-1) has been proven to stimulate angiogenesis and have anti-inflammatory and anti-apoptotic actions [9]. Moreover, it has indirect effects on the cardiovascular system by increasing insulin sensitivity. In the PRIME study a link between low levels of circulating IGF-1 and a high prevalence of IHD in healthy subjects has been suggested [10]. In our research we focused on IGFBP7, which interacts with IGF-1 and with insulin. By binding with IGF-1, it neutralizes its activity. What is more, it may interfere with the biological response of insulin, and it has many IGF-independent actions. Its role in atherosclerosis development remains unclear and requires further studies. According to our previous research, IGFBP7 seems to be a good marker of IHD occurrence-its concentration was significantly higher in patients with coronary lesions than in healthy subjects. However, its levels do not reflect IHD advancement [11].

The aim of the study was to determine the associations between IGFBP7 concentrations and concentrations of troponin T, NT-proBNP and serum parameters of kidney function in patients with stable IHD.

\section{Materials and Methods}

\subsection{The Study Population}

The IHD group included 88 patients (19 females-22\%) with established IHD approximately a year after myocardial infarction or percutaneous coronary intervention. The population group - which has no history of IHD (65 subjects, 24 females, 38.8\%) -was chosen based on age and gender from a larger cohort representative of the local population. The study group comprised 88 patients aged $63.2 \pm 7.8$ recruited to one of the cardiology centers taking part in multinational registry EUROASPIRE V assessing the efficacy of secondary prevention measures in Europe [12]. The criteria for recruitment and exclusion have been described previously [13]. In short, all patients had been hospitalized 6-18 months prior to their enrolment in the study. After enrolment, detailed medical history was taken as well as a large number of imaging and functional tests of cardiovascular system and carbohydrate metabolism. The control group $(n=65)$ was recruited from participants of the population-based cohort study Bialystok PLUS [14], which represents general local population in age, 20-80. We excluded patients with a history of cardiovascular disease (myocardial infarction, coronary or peripheral vascular intervention, stroke and peripheral vascular disease) and chose patients based on their age, gender and BMI to match the study group.

\subsection{Biochemical Evaluation}

In order to obtain analyzed biochemical parameters and IGFBP 7 concentration, the blood was drawn via a closed system of the Monovette type (Sarstedt Company, Nümbrecht, Germany). The biochemical parameters were determined within $2 \mathrm{~h}$ after the material's collection. Troponin T (TnT) and NT-proBNP analysis was performed using electrochemiluminescence method on the Cobas e411 (ROCHE Diagnostics International Ltd., Rotkreuz, Switzerland). The blood samples ( $5 \mathrm{~mL}$ ) used for IFGBP7 determination were left for $2 \mathrm{~h}$ at room temperature to allow clot formation. Then, they were centrifuged at $1000 \times g$ for $20 \mathrm{~min}$ at room temperature, and obtained supernatant serum was frozen and 
stored at $-80^{\circ} \mathrm{C}$. The concentration of IGFBP7 was established with commercially available ELISA kit 7 (insulin growth-factor-binding protein; USCN Life Science Inc., Wuhan, Hubei, China). C-peptide was determined by electrochemiluminescence assay (ECLIA) on Cobas e411 equipment (ROCHE Diagnostics International Ltd., Rotkreuz, Switzerland).

In all participants oral glucose tolerance test (OGTT) and blood pressure and antropometric measurements were performed as described previously [13].

\subsection{Statistical Analysis}

The mean values and standard deviations for quantitative variables as well as the quantitative and percentage distribution for qualitative variables were calculated. Pearson's correlation coefficient for categorical variables of normal distribution and Spearman's correlation coefficient for variables not satisfying normal distribution criteria were calculated. To compare the groups, the statistical analysis of normal distribution variables estimated with the use of the Kolmogorov compatibility test was carried out using the unpaired Student's test and the Mann-Whitney test for variables inconsistent with a normal distribution. The comparison of qualitative variables between the groups was performed using the Chi2 test. A multivariate analysis of the factors affecting IGFBP7 concentration was performed using general linear model A. Value of $p<0.05$ was considered statistically significant. The statistical analysis was carried out using Statistica 12.0 PL software (StatSoft, Cracow, Poland).

\section{Results}

Patients in the IHD group presented a significantly higher concentration of IGFBP7 than those in the population group $(1.76 \pm 1 \mathrm{ng} / \mathrm{mL}$ vs. $1.43 \pm 0.44 \mathrm{ng} / \mathrm{mL}$, respectively, $p=0.019$ ), as well as a significantly higher concentration of creatinine, urea, glucose, insulin, TnT and NTproBNP (detailed characteristics of the studied group are presented in Table 1).

Table 1. Characteristics of analyzed groups.

\begin{tabular}{|c|c|c|c|}
\hline Variables & $\begin{array}{c}\text { IHD } \\
(n=88)\end{array}$ & Population Group $(n=65)$ & $p$ \\
\hline Age (years) & $63.2(7.8)$ & $61.2(8.2)$ & NS \\
\hline Male gender $(\mathrm{n}, \%)$ & $69(78 \%)$ & $41(61.2 \%)$ & NS \\
\hline BMI & $29.8(5.5)$ & $28.7(4.1)$ & NS \\
\hline IGFBP7 (ng/mL) & $1.76(1.04)$ & $1.41(0.45)$ & 0.019 \\
\hline Creatinine $(\mu \mathrm{mol} / \mathrm{L})$ & $92.2(41.4)$ & $80.5(16.8)$ & $<0.0001$ \\
\hline Urea $(\mathrm{mg} / \mathrm{dL})$ & $38(15.2)$ & $31.9(8.4)$ & $<0.0001$ \\
\hline Glucose (mg/dL) & $114.7(36.7)$ & $95.9(14.2)$ & $<0.0001$ \\
\hline Insulin $(\mu \mathrm{U} / \mathrm{mL})$ & $15.03(9.5)$ & $12.8(6.4)$ & $<0.0001$ \\
\hline C-peptide (ng/mL) & $3.38(1.6)$ & $2.83(1)$ & NS \\
\hline $\operatorname{TnT}(\mathrm{pg} / \mathrm{mL})$ & $13.57(13.6)$ & $7.5(3.7)$ & $<0.0001$ \\
\hline NT-proBNP (pg/mL) & $355.2(538.7)$ & $98.2(97.9)$ & $<0.0001$ \\
\hline
\end{tabular}

In both groups there was a significant correlation between IGFBP7 and serum parameters of kidney function (creatinine concentration: population gr. $\mathrm{r}=0.45, p<0.001$, IHD gr. $\mathrm{r}=0.86, p<0.0001$; urea concentration: population gr. $\mathrm{r}=0.51, p<0.0001$, IHD gr. $\mathrm{r}=0.71, p<0.00001$ ), as seen in Figure 1a,b. Interestingly, no correlation between IGFBP7 and microalbuminuria or the albumin to creatinine ratio in urine was found.

There was no significant correlation between IGFBP7 concentration and HBA1c levels in either group. Only the C-peptide concentration was considered statistically significant, but it was only weakly correlated with IGFBP-7 levels in patients with IHD ( $\mathrm{r}=0.27$, $p=0.01, \mathrm{C}$-peptide $\mathrm{r}=0.28, p<0.001$ )-Figure 1c. Moreover, diabetic patients treated with insulin presented significantly higher IGFBP7 concentrations than diabetics treated with oral drugs ( $3.81 \pm 3.2 \mathrm{ng} / \mathrm{mL}$ vs. $1.51 \pm 0.5 \mathrm{ng} / \mathrm{mL})$-Figure 2. 

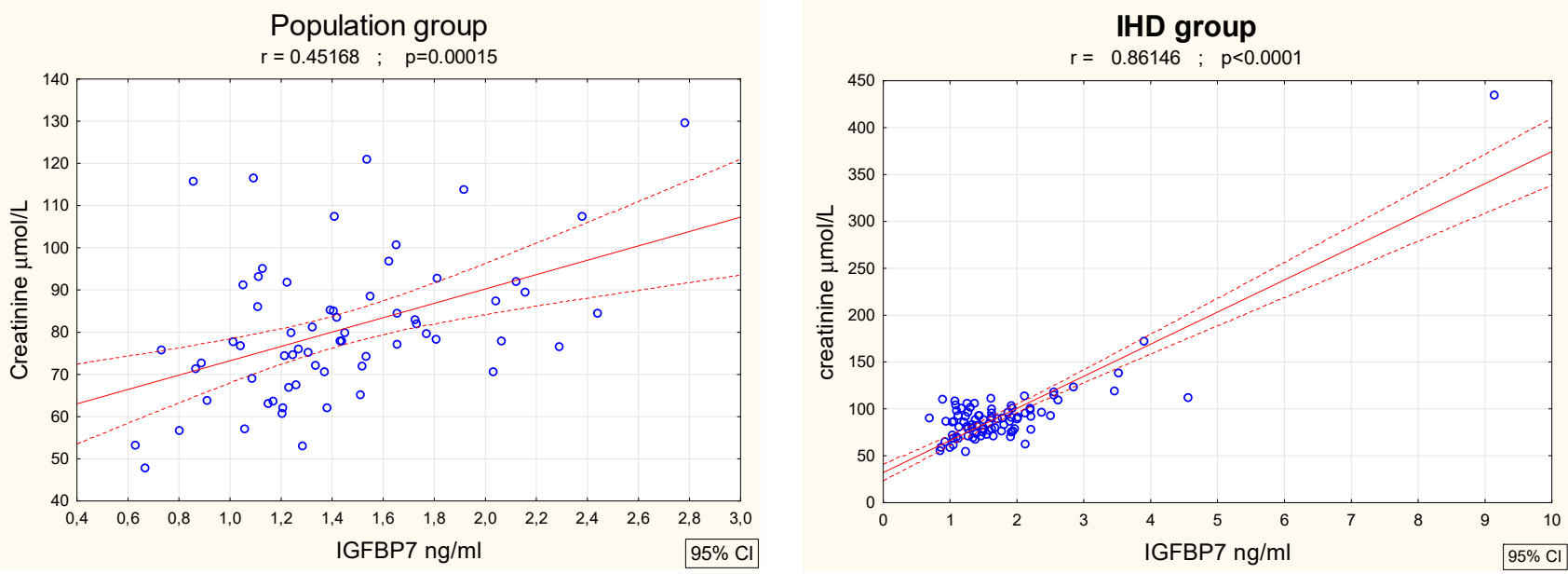

(a)
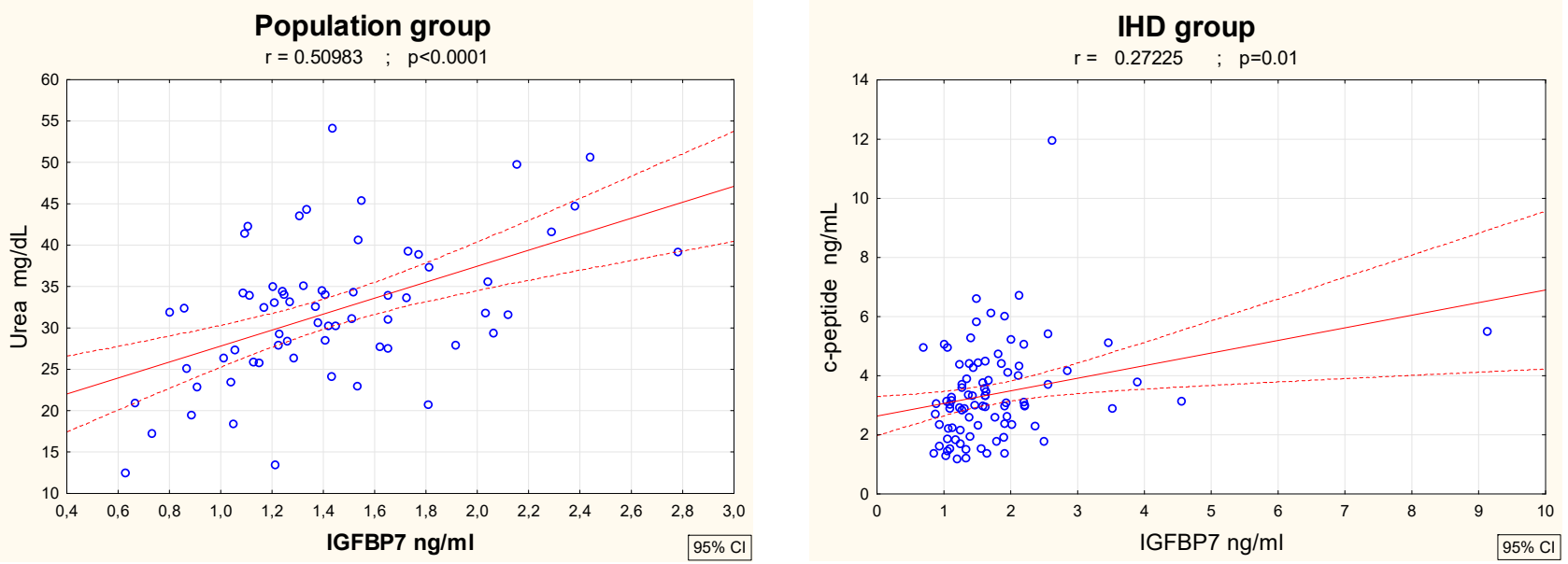

(b)
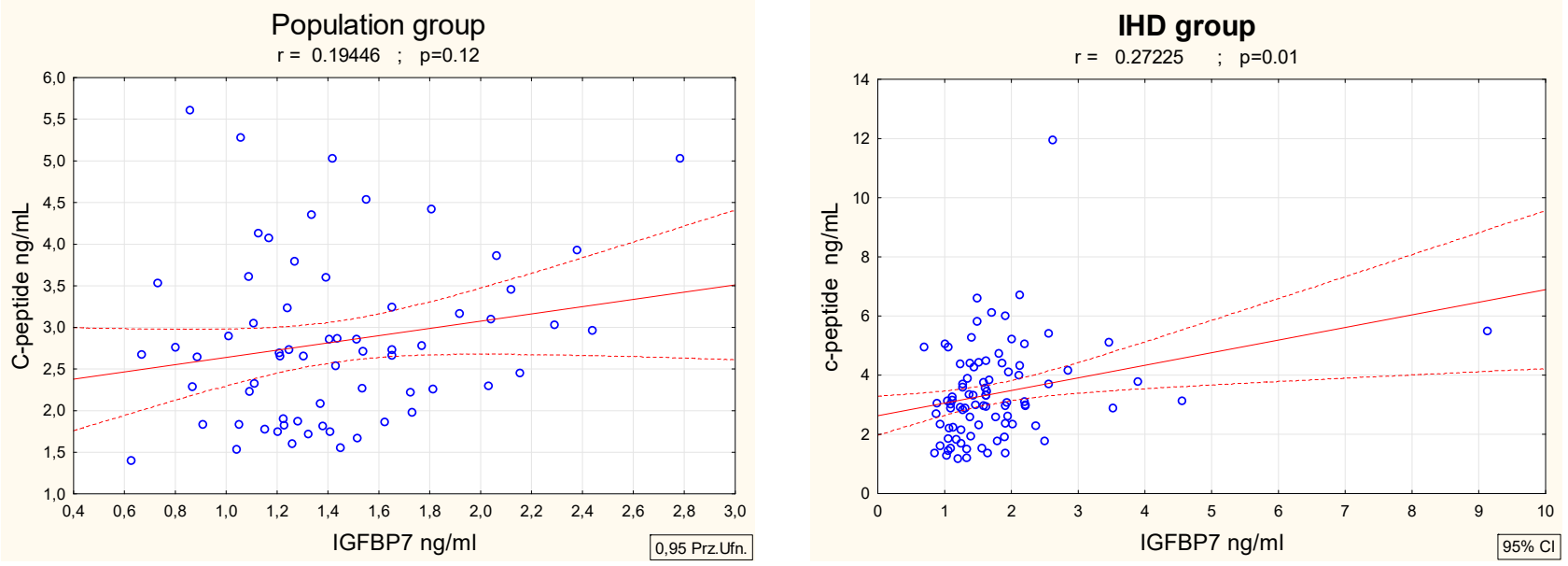

(c)

Figure 1. Correlations between concentration of IGFBP7 and concentrations of creatinine (a), urea (b) and c-peptide $(c)$ in population group $(n=65)$ and ischemic heart disease patients $(n=88)$. 


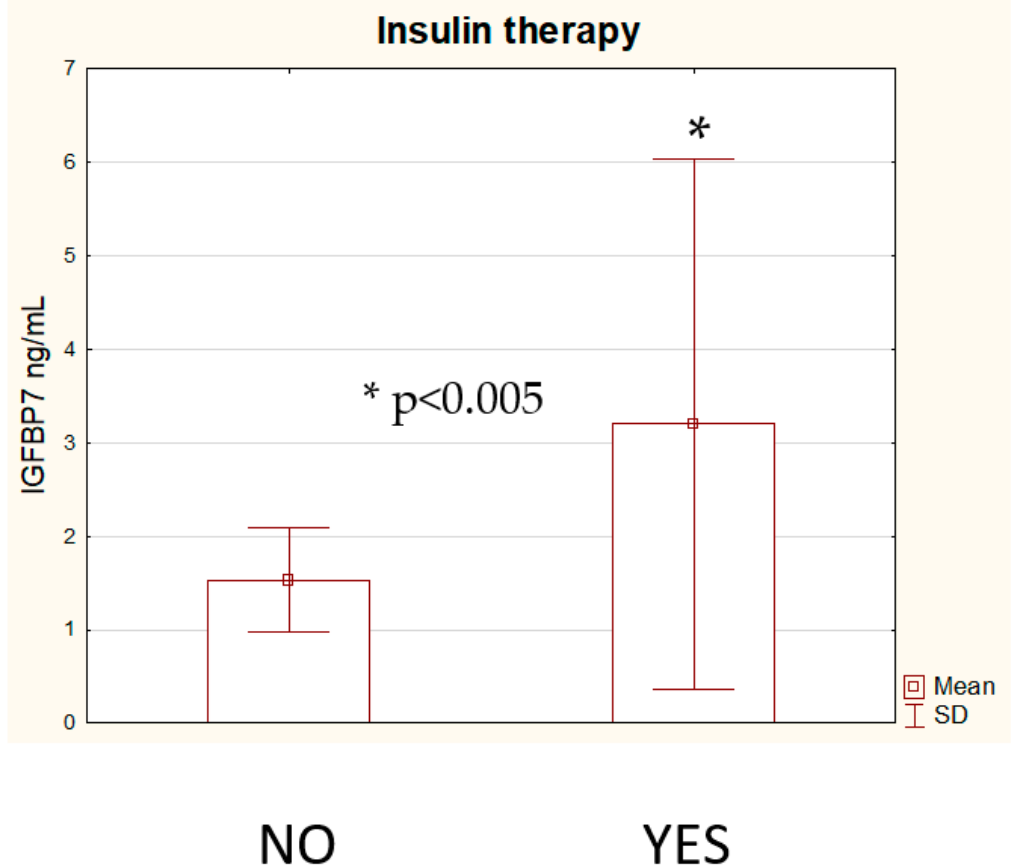

Figure 2. IGFBP7 concentration in patients on insulin therapy.

We also found that in the IHD group there was a significant correlation between IGFBP7 concentration and the markers of heart injury/overload, TnT and NT-BNP $(\mathrm{r}=0.76$, $p<0.001$ and $\mathrm{r}=0.72, p<0.001$; respectively), as seen in Figure 3a,b.
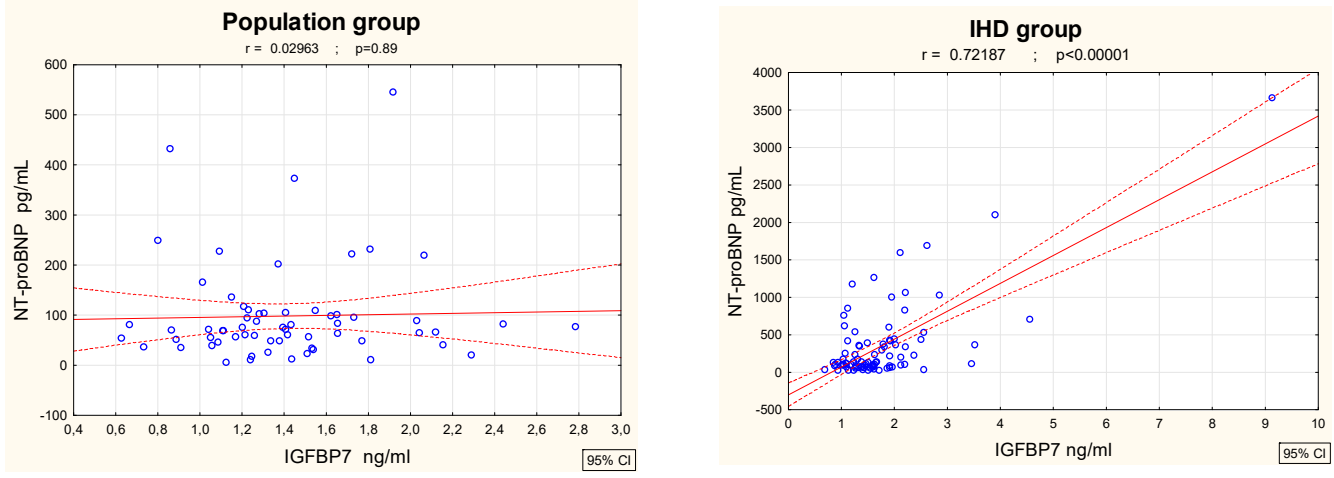

(a)
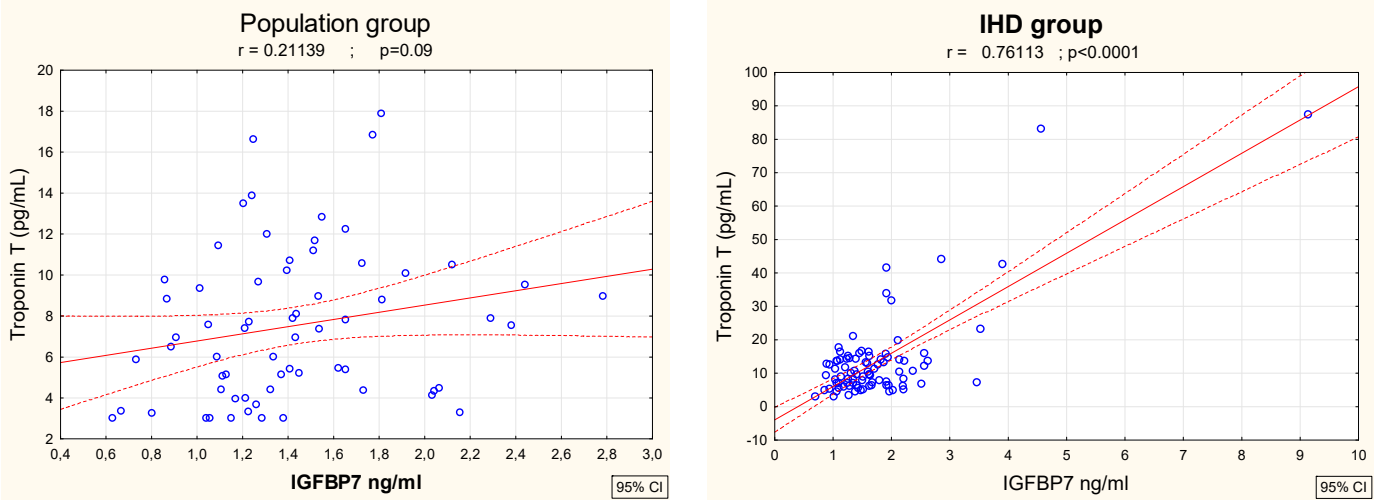

(b)

Figure 3. Correlations between concentration of IGFBP7 and concentrations of NTproBNP (a) and troponin $T(b)$ in population group $(n=65)$ and ischemic heart disease patients $(n=88)$. 
Multiple regression modeling of factors influencing IGFBP7 in the combined population of both groups showed that concentrations of urea, creatinine and TnT were independent predictors, while a diagnosis of ischemic heart disease and NT-BNP concentration did not have a statistically significant influence on the IGFBP7 concentration (Table 2). This multivariable model yielded very good prediction power $\left(\mathrm{R}^{2}=0.77\right)$, and it decreased only slightly after the removal of variables that were not statistically significant $\left(R^{2}=0.76\right)$. Neither a previous diabetes diagnosis nor laboratory parameters of glucose metabolism (glucose, insulin and C-peptide concentrations in an oral glucose tolerance test) were found to be independently associated with IGFBP7 concentration in the multivariate analysis.

Table 2. Multiple regression model of factors influencing concentration of IGFBP7 in combined groups.

\begin{tabular}{ccc}
\hline $\begin{array}{c}\text { Multiple Regression Analysis } \\
\mathbf{R}^{2} \text { for the Multivariate Model 0.77 }\end{array}$ & Beta & $p$ \\
\hline Urea & 0.45 & $<0.0001$ \\
Creatinine & 0.23 & $<0.0001$ \\
TnT & 0.23 & $<0.001$ \\
NT-BNP & 0.1 & 0.055 \\
Ischemic heart disease & -0.02 & 0.5 \\
\hline
\end{tabular}

\section{Discussion}

IGFBP7 has been recently identified as a novel biomarker for heart failure and cardiac hypertrophy. Intensive research according to its role in developing and progressing obesity, diabetes, acute kidney injury (AKI), cancers, chronic obstructive pulmonary disease (COPD) and other diseases has been conducted [15-17].

IGFBP7's role in atherosclerosis development is yet to be determined. In our previously published research, which is, as far as we know, the first one handling that issue, we observed that IGFBP7 seems to be a good marker of IHD occurrence [11]. Its levels were significantly higher in the group of patients with myocardial infarction (MI) and coronary artery disease (CAD) than in the control group of healthy subjects. However, there were no statistically significant differences in IGFBP7 concentration between patients with stable IHD and MI [11]. The results obtained from our current study, indicating significantly higher levels of IGFBP7 in the group of patients with IHD compared to the population group, confirm the possible role of this protein in atherosclerosis development.

An increased concentration of IGFBP7 is also associated with insulin resistance (IR) and the risk of metabolic syndrome (MetS) $[7,18]$. This protein has a high affinity to insulin (500 times higher compared to other IGFBPs) and competes with the insulin receptor (InsR) for binding insulin, which substantially reduces the serum level of free insulin, blocks the binding of insulin to the InsR and diminishes the physiological response to insulin. As a result, it contributes to insulin resistance, diabetes and cardiovascular diseases development $[7,18]$. Patients with MetS and IR have a significantly higher serum concentration of IGFBP7 than healthy individuals [7]. In our research we have observed that diabetic patients treated with insulin presented significantly higher IGFBP7 concentrations, which is consistent with previous findings on IGFBP7's role in IR development. Moreover, we found that IGFBP7 levels significantly correlated with C-peptide concentration in patients with IHD, which has not been reported in any previous research. C-peptide is a short 31-amino-acid polypeptide that connects insulin's A-chain to its B-chain in the proinsulin molecule. Measurements of its concentration reflect the actual insulin production through the pancreas. Interestingly, in our study there was no significant correlation between IGFBP7 concentration and HBA1C levels in either group of patients.

In our research we also found a significant correlation between IGFBP7 and serum parameters of kidney function (creatinine and urea) in both groups of patients. It is consistent with recent research, which has proven that IGFBP7, together with the tissue inhibitor of metalloproteinases-2 (TIMP-2), is a novel marker of tubular damage, and 
it can be used for the early detection of acute-kidney-injury (AKI)-endangered patients. Urinary TIMP2*IGFBP and IGFBP7 were proven to be the most accurate biomarkers for the prediction and renal outcome in patients with AKI [19-21]. However, we have not reported any correlation between IGFBP7 and the albumin to creatinine ratio in urine.

Elevated levels of IGFBP7 were also found in patients with heart failure [22,23]. Moreover, a combination of IGBP7 and NTproBNP correlated with shorter event-free survival [24]. In our study there was a significant correlation between IGFBP7 and NTproBNP concentration in patients with IHD. According to previous findings, it seems that left ventricular filling pressure may be an important trigger for IGFBP7 expression and release because of its strong independent association with an increased left atrial volume index (LAVI) $[25,26]$. We have not assessed ejection fraction (EF) in our research, but our previous findings showed no statistically significant differences of IGFBP7 concentrations between low-EF $(<50 \%)$ and high-EF $(>50 \%)$ patients [11].

An increase in high-sensitivity troponin $\mathrm{T}$ (hs-TnT) occurs not only in acute heart injury (such as MI or pulmonary embolism) but also in patients with stable chronic HF. According to previous research, elevated hs-Tn in this group of patients is caused by chronic low-grade cardiac ischemia [27]. It is consistent with our data that patients with IHD had higher TnT concentrations, which also significantly correlated with IGFBP7 levels. It seems that IGFBP7 could be considered as a plasma biomarker of chronic, ongoing myocardium damage, especially in patients with IHD, when ischemic cardiomyocytes are replaced by fibrous tissue.

To summarize our research, it seems that the multi-marker approach, combining measuring well-established cardiac-specific markers such as NTproBNP and troponin T with "new" ones such as IGFBP7 or galectin-3 [28], will become a daily routine in our future medical practice.

\section{Conclusions}

Elevated IGFBP7 levels are associated not only with established risk factors of heart failure such as coronary atherosclerosis, kidney function and glucose metabolism disturbances, but also with a marker of myocardial damage or overload, TnT.

IGFBP7 is a new promising marker in cardiovascular medicine, and its role should be further investigated, not only in respect to vascular changes but also heart failure and left ventricular dysfunction.

Author Contributions: Conceptualization, A.L. and K.K.; methodology, K.K. and A.L.; software, M.K. (Marcin Kondraciuk); validation, A.L. and K.K.; formal analysis, K.K. and A.L.; investigation, A.L., A.S. and K.K.; data curation, M.Ł.; writing-original draft preparation, A.L., A.S. and K.K.; writing - review and editing, K.P.-K.; visualization, K.K. and A.S.; supervision, T.H.; project administration, I.K. and M.K. (Małgorzata Knapp); funding acquisition, K.K. and A.L. All authors have read and agreed to the published version of the manuscript.

Funding: This study was a statutory project of the Medical University of Bialystok.

Institutional Review Board Statement: Consent for the study was given by the Bioethics Committee Nr R-I-002/108/2016.

Informed Consent Statement: Informed consent was obtained from all subjects involved in the study.

Data Availability Statement: Data may be available on reasonable scientific request to the senior author.

Conflicts of Interest: The authors declare no conflict of interest.

\section{Abbreviations}

AHF-acute heart failure; AKI—acute kidney injury; BMI-Body Mass Index; CAD—coronary artery disease; COPD—chronic obstructive pulmonary disease; EF—left ventricular ejection fraction; $\mathrm{HF}$-heart failure; $\mathrm{HFpEF}-\mathrm{HF}$ with preserved ejection fraction; HFrEF-HF with reduced ejection fraction; hs-Tn — high-sensitivity troponin; IGF-insulinlike growth factor; IGFBP7-insulin-like growth-factor-binding protein 7; IGFBPs—insulin- 
like growth-factor-binding proteins; IGF-R_-IGF receptor; IHD_-ischemic heart disease; Ins$\mathrm{R}$-insulin receptor; IR-insulin resistance; LAVI-left atrium volume index; LV-left ventricular; MetS—metabolic syndrome; MI-myocardial infarction; NGAL-neutrophil-gelatinaseassociated lipocalin; NSTEMI-non-ST-elevation MI; NT-proBNP-N-terminal pro-B-type natriuretic peptide; OGTT-oral glucose tolerance test, $\mathrm{PCI}$ - percutaneous coronary intervention; PSF-prostacyclin-stimulating factor; sST2 - soluble suppression of tumorigenicity-2; STEMI—ST elevation MI; TnT_troponin T; TAF—tumor adhesion factor; TGF- $\beta$ —-transforming growth factor $\beta$; TIMP-2-Tissue inhibitor of metalloproteinases-2.

\section{References}

1. Anuradha, L.; Akshay, S.D. The Role of Coronary Artery Disease in Heart Failure. Heart Fail. Clin. 2014, 10, 353-365. [CrossRef]

2. Shahab, K.; Farshad, F.; John, O.; Majid, E.; Andrew, M. World-wide risk factors for heart failure: A systematic review and pooled analysis. Int. J. Cardiol. 2013, 168, 1186-1194. [CrossRef]

3. Khan, M.A.; Hashim, M.J.; Mustafa, H.; Baniyas, M.Y.; Al Suwaidi, S.K.B.M.; AlKatheeri, R.; Alblooshi, F.M.K.; Almatrooshi, M.E.A.H.; Alzaabi, M.E.H.; Al Darmaki, R.S.; et al. Global Epidemiology of Ischemic Heart Disease: Results from the Global Burden of Disease Study. Cureus 2020, 12, e9349. [CrossRef]

4. Xiaoming, J.; Wensheng, S.; Ron, C.H.; Vijay, N.; Kunihiro, M.; Aaron, R.F.; Gerardo, H.; David, J.C.; Scott, D.S.; Eric, B.; et al. High-Sensitivity Troponin I and Incident Coronary Events, Stroke, Heart Failure Hospitalization, and Mortality in the ARIC Study. Circulation 2019, 139, 2642-2653. [CrossRef]

5. Peder, L.M.; Brian, C.; Christie, M.B.; Elizabeth, S.; Helge, R.; Torbjørn, O.; Scott, D.S.; Hicham, S.; Amil, M.S. Association Between Circulating Troponin Concentrations, Left Ventricular Systolic and Diastolic Functions, and Incident Heart Failure in Older Adults. JAMA Cardiol. 2019, 4, 997-1006. [CrossRef]

6. $\quad$ Rasmus, R.; Pardeep, S.J.; Søren, L.K.; Akshay, S.D.; Lars, K.; Jean, L.R.; Scott, D.S.; Karl, S.; Michael, R.Z.; Milton, P.; et al. The prognostic value of troponin $\mathrm{T}$ and $\mathrm{N}$-terminal pro B-type natriuretic peptide, alone and in combination, in heart failure patients with and without diabetes. Eur. J. Heart Fail. 2019, 21, 40-49. [CrossRef]

7. Szyszkowska, A.; Knapp, M.; Kaminski, K.; Lisowska, A. Insulin-like growth factor-binding protein 7 (IGFBP7): Novel, independent marker of cardiometabolic diseases? Postepy Hig. Med. Dosw. 2019, 73, 735-740. [CrossRef]

8. Chen, D.; Yoo, B.K.; Santhekadur, P.K.; Gredler, R.; Bhutia, S.K.; Das, S.K.; Fuller, C.; Su, Z.Z.; Fisher, P.B.; Sarkar, D. Insulin-like growth factor binding protein-7 (IGFBP-7) functions as a potential tumor suppressor in hepatocellular carcinoma (HCC). Clin. Cancer. Res. 2011, 17, 6693-6701. [CrossRef] [PubMed]

9. Higashi, Y.; Gautam, S.; Delafontaine, P.; Sukhanov, S. IGF-1 and cardiovascular disease. Growth Horm. IGF Res. 2019, 45, 6-16. [CrossRef] [PubMed]

10. Ruidavets, J.B.; Luc, G.; Machez, E.; Genoux, A.L.; Kee, F.; Arveiler, D.; Morange, P.; Woodside, J.V.; Amouyel, P.; Evans, A.; et al. Effects of insulin-like growth factor 1 in preventing acute coronary syndromes: The PRIME study. Atherosclerosis 2011, 218, 464-469. [CrossRef] [PubMed]

11. Lisowska, A.; Święcki, P.; Knapp, M.; Gil, M.; Musiał, W.J.; Kamiński, K.; Hirnle, T.; Tycińska, A. Insulin-like growth factor-binding protein 7 (IGFBP 7) as a new biomarker in coronary heart disease. Adv. Med. Sci. 2019, 64, 195-201. [CrossRef] [PubMed]

12. De Backer, G.; Jankowski, P.; Kotseva, K.; Mirrakhimov, E.; Reiner, Ž.; Rydén, L.; Tokgözoğlu, L.; Wood, D.; De Bacquer, D.; EUROASPIRE V collaborators. Management of dyslipidaemia in patients with coronary heart disease: Results from the ESC-EORP EUROASPIRE V survey in 27 countries. Atherosclerosis 2019, 285, 135-146. [CrossRef] [PubMed]

13. Paniczko, M.; Chlabicz, M.; Jamiołkowski, J.; Sowa, P.; Szpakowicz, M.; Łapińska, M.; Kondraciuk, M.; Ptaszyńska-Kopczyńska, K.; Raczkowski, A.; Szpakowicz, A.; et al. Impact of Pulse Wave Velocity and Parameters Reflecting Android Type Fat Distribution on Left Ventricular Diastolic Dysfunction in Patients with Chronic Coronary Syndromes. J. Clin. Med. 2020, 9, 3924. [CrossRef] [PubMed]

14. Chlabicz, M.; Dubatówka, M.; Jamiołkowski, J.; Sowa, P.; Łapińska, M.; Raczkowski, A.; Łaguna, W.; Moniuszko-Malinowska, A.M.; Waszkiewicz, N.; Kowalska, I.; et al. Subjective well-being in non-obese individuals depends strongly on body composition. Sci. Rep. 2021, 11, 21797. [CrossRef] [PubMed]

15. Januzzi, J.L.; Packer, M.; Claggett, B.; Liu, J.; Shah, A.M.; Zile, M.R.; Pieske, B.; Voors, A.; Gandhi, P.U.; Prescott, M.F.; et al. IGFBP7 (insulin-like growth factor-binding protein-7) and neprilysin inhibition in patients with heart failure. Circ. Heart Fail. 2018, 11, e005133. [CrossRef]

16. Ruan, W.; Wu, M.; Shi, L.; Li, F.; Dong, L.; Qiu, Y.; Wu, X.; Ying, K. Serum levels ofIGFBP7 are elevated during acute exacerbation inCOPD patients. Int. J. Chronic Obstr. Pulm. Dis. 2017, 12, 1775-1780. [CrossRef]

17. Bolomsky, A.; Hose, D.; Schreder, M.; Seckinger, A.; Meißner, T.; Klein, B.; Heintel, D.; Pfeifer, S.; Ludwig, H.; Zojer, N. Insulinlike growth factor binding protein 7 (IGFBP7) is downregulated in multiple myeloma with consequneces for myeloma cell growth and bone disease. Blood 2012, 120, 3947. [CrossRef]

18. Liu, Y.; Wu, M.; Ling, J.; Cai, L.; Zhang, D.; Gu, H.F.; Wang, H.; Zhu, Y.; Lai, M. Serum IGFBP7 levels associate with insulin resistance and the risk of metabolic syndrome in a Chinese population. Sci. Rep. 2015, 5, 10227. [CrossRef] [PubMed] 
19. Aregger, F.; Uehlinger, D.E.; Witowski, J.; Brunisholz, R.A.; Hunziker, P.; Frey, F.J.; Jörres, A. Identification of IGFBP-7 by urinary proteomics as a novel prognostic marker in early acute kidney injury. Kidney Int. 2014, 85, 909-919. [CrossRef] [PubMed]

20. Jia, H.M.; Huang, L.F.; Zheng, Y.; Li, W.X. Prognostic value of cell cycle arrest biomarkers in patients at high risk for acute kidney injury: A systematic review and meta-analysis. Nephrology 2017, 22, 831-837. [CrossRef] [PubMed]

21. Schanz, M.; Shi, J.; Wasser, C.; Alscher, M.D.; Kimmel, M. Urinary [TIMP-2] $\times$ [IGFBP7] for risk prediction of acute kidney injury in decompensated heart failure. Clin. Cardiol. 2017, 40, 485-491. [CrossRef] [PubMed]

22. Gandhi, P.U.; Chow, S.L.; Rector, T.S.; Krum, H.; Gaggin, H.K.; McMurray, J.J.; Zile, M.R.; Komajda, M.; McKelvie, R.S.; Carson, P.E.; et al. Prognostic value of insulin-like growth factor-binding protein 7 in patients with heart failure and preserved ejection fraction. J. Card. Fail. 2017, 23, 20-28. [CrossRef] [PubMed]

23. Barroso, M.C.; Kramer, F.; Greene, S.J.; Scheyer, D.; Köhler, T.; Karoff, M.; Seyfarth, M.; Gheorghiade, M.; Dinh, W. Serum insulin-like growth factor-1 and its binding protein-7: Potential novel biomarkers for heart failure with preserved ejection fraction. BMC Cardiovasc. Disord. 2016, 16, 199. [CrossRef] [PubMed]

24. Ibrahim, N.E.; Afilalo, M.; Chen-Tournoux, A.; Christenson, R.H.; Gaggin, H.K.; Hollander, J.E.; Kastner, P.; Levy, P.D.; Mang, A.; Masson, S.; et al. Diagnostic and prognostic utilities of insulin-like growth factor binding protein-7 in patients with dyspnea. $J$. Am. Coll. Cardiol. HF 2020, 8, 415-422. [CrossRef] [PubMed]

25. Kalayci, A.; Peacock, W.F.; Nagurney, J.T.; Hollander, J.E.; Phillip, D.; Levy, P.D. Echocardiographic assessment of insulin-like growth factor binding protein-7 and early identification of acute heart failure. ESC Heart Fail. 2020, 7, 1664-1675. [CrossRef] [PubMed]

26. Liang, F.; Wu, J.; Garami, M.; Gardner, D.G. Mechanical strain increases expression of the brain natriuretic peptidegene in rat cardiac myocytes. J. Biol. Chem. 1997, 272, 28050-28056. [CrossRef]

27. Omland, T.; Rosjo, H.; Giannitsis, E.; Agewall, S. Troponins in heart failure. Clin. Chim. Acta 2015, 443, 78-84. [CrossRef] [PubMed]

28. Święcki, P.; Sawicki, R.; Knapp, M.; Kamiński, K.A.; Ptaszyńska-Kopczyńska, K.; Sobkowicz, B.; Lisowska, A. Galectin-3 as the Prognostic Factor of Adverse Cardiovascular Events in Long-Term Follow up in Patients after Myocardial Infarction-A Pilot Study. J. Clin. Med. 2020, 9, 1640. [CrossRef] 